\title{
EXPERIMENTAL ASSESSMENT OF STRENGTHENING STRATEGY TO IMPROVE THE MASONRY INFILLS OUT-OF-PLANE BEHAVIOUR THROUGH TEXTILE REINFORCED MORTAR
}

\author{
Furtado André ${ }^{1}$, Rodrigues Hugo ${ }^{2}$, Melo José ${ }^{3}$, Arêde António ${ }^{4}$, Varum Humberto ${ }^{5}$ \\ ${ }^{1} \mathrm{PhD}$ Student, CONSTRUCT-LESE, Faculdade de Engenharia da Universidade do Porto, Porto, Por- \\ tugal, afurtado@fe.up.pt \\ ${ }^{2}$ Senior Lecturer, RISCO - ESTG, Polytechnic Institute of Leiria, Portugal, hugo.f.rodrigues@iplei- \\ ria.pt \\ ${ }^{3}$ Post-Doctoral Research Fellow, CONSTRUCT-LESE, Faculdade de Engenharia da Universidade do \\ Porto, Porto, Portugal, josemelo@fe.up.pt \\ ${ }^{4}$ Associate Professor, CONSTRUCT-LESE, Faculdade de Engenharia da Universidade do Porto, \\ Porto, Portugal, aarede@fe.up.pt \\ ${ }^{5}$ Full Professor, CONSTRUCT-LESE, Faculdade de Engenharia da Universidade do Porto, Porto, Por- \\ tugal,hvarum@fe.up.pt
}

\begin{abstract}
Throughout the last years, the study of the masonry infill walls out-of-plane behavior is being observed by the scientific community with special attention, mainly due to damages observed during post-earthquake scenarios, where several number of damages and out-of-plane collapses of infill panels were found. Different causes are pointed to justify the seismic vulnerability of these type of elements, most of all related to deficient construction practices, which are nowadays still applicable Based on this motivation, two experimental quasi-static, full-scale, out-ofplane tests were carried out on RC frames that were built and infilled with a thin masonry wall made up of horizontal hollow clay bricks. The first specimen is representative of the enclosure of a typical existing RC building in the Southern countries in its "as-built" condition. The second specimen was strengthened with textile-reinforced mortar using glass fiber mesh. Both specimens were subjected to semi-cyclic (loading-unloading-reloading) history of imposed displacements by means of small pneumatic jacks through a uniform distributed load. Experimental results will be presented and detailed in terms of out-of-plane force-displacement responses and damage evolution. In the end, the results of the tests are compared to assess the effectiveness of the strengthening technique.
\end{abstract}

Keywords: masonry infill walls, out-of-plane testing, strengthening strategies, textile-reinforced mortar. 


\section{INTRODUCTION}

One of the major challenges concerning the earthquake risk mitigation is the vulnerability assessment of existing buildings that were not designed according to modern codes and the development of effective retrofit techniques. Over the last few years, it is visible an increase of interest regarding the study of the masonry infill walls and their influence in the response of reinforced concrete buildings when subjected to earthquakes. Recent post-earthquake damages survey reports recognized that the masonry infill walls played an important role in the seismic response of the reinforced concrete buildings. Similarly, the infill panels' seismic behavior is being characterized by extensive damages and collapses due to combined in-plane and out-ofplane (OOP) loadings. The infill panels' OOP collapse is being responsible by innumerous fatalities, material and economical losses [1-3].

Different authors reported that the masonry infill walls' OOP behavior is strongly affected by the following issues $[4,5]$ : existence or not of connection between the panel and the reinforced concrete frame elements; existence of not of connection between leafs (in case of doubleleaf infill walls); inadequate panel' width support (very common constructive procedure adopted for thermal bridges' prevention), boundary conditions, panel slenderness, inadequate construction execution of the last horizontal bed joint and lastly, the existence of previous damage. The infill panels' collapse can result in plan and/or vertical irregularities, which can trigger global failure mechanisms.

Considering the small number of experimental and numerical studies in this field and based on the well common masonry infill walls' presence in the reinforced concrete buildings in Portugal, it is fundamental to carry out studies to characterize the seismic behavior of these panels and to develop efficient retrofit strategies that will improve their performance and prevent their collapse when subjected to earthquakes.

The present work focusses in the assessment of the efficiency of a strengthening technique based on textile-reinforced mortar (TRM) to improve the OOP behavior of a full-scale infill panel. For this, two specimens tested to OOP loadings applied by pneumatic actuators. The first specimen is representative of the enclosure of a typical existing RC building in the Southern countries in its "as-built" condition. The second specimen was strengthened with textile-reinforced mortar using glass fiber mesh. Experimental results will be presented and detailed in terms of out-of-plane force-displacement responses and damage evolution. In the end, the results of the tests are compared to assess the effectiveness of the strengthening technique.

\section{EXPERIMENTAL CAMPAIGN}

\subsection{Specimens' description}

The experimental campaign was composed by two quasi-static OOP tests of full-scale infill panels by using pneumatic actuators that applied a uniform load. The geometric dimensions of the tested panels are $4.20 \times 2.30 \mathrm{~m}$ (length and height, respectively), representative of building stock existing in the Southern European Countries [6] (Figure 1). The infill panel is surrounded by an envelope reinforced concrete frame, which is composed by columns and beams with sections $30 \times 30 \mathrm{~cm}^{2}$ and $30 \times 50 \mathrm{~cm}^{2}$, respectively.

Both panels were built with horizontal hollow clay bricks which geometric dimensions are 150x200x300mm (thickness, height and length respectively), without any mechanical connection and any gap between the panel and the envelope frame. Both panels were built aligned with the external side of the RC beam as well as using a typical workmanship. Concerning the remaining materials, it was selected a traditional mortar type M5, concrete class C20/25 and reinforcement steel class A500. 


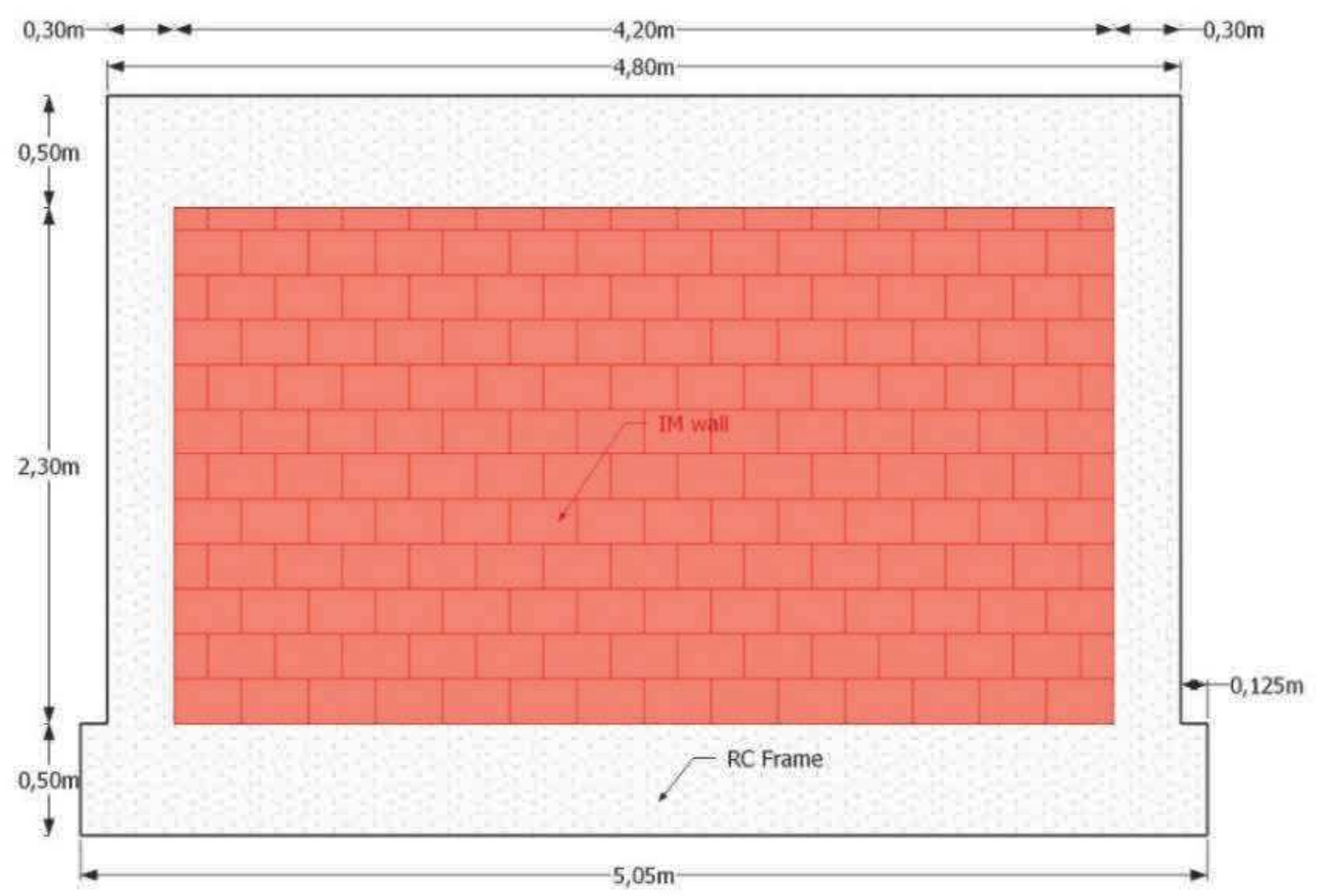

Figure 1: Infilled RC frame specimen dimensions (units in meters): general dimensions.

The as-built panel, herein designated "INF_09" was built and tested until the collapse. After the panel removal, it was built a new panel, which was strengthened 10 days after. This panel, herein designated "INF_10" was strengthened using TRM solution with a glass fiber net. Fassa Bortolo provided the net selected, which was the FASSANET ARG 40, with a matrix $4 \times 4 \mathrm{~cm}$ and a tensile strength equal to $56.25 \mathrm{kN} / \mathrm{m}$. Metallic connectors ( $\phi 6 \mathrm{~mm}$ and $8 \mathrm{~cm}$ length) ensured the connection of the net to the panel and that two of the brick walls were crossed by (Figure $2 \mathrm{a}$ and $2 \mathrm{~b}$ ). In order to ensure a better fixation of the net to the wall, plastic discs with a diameter of $6 \mathrm{~cm}$ were used in the top of the metallic connector. Regarding the anchorage of the net to the $\mathrm{RC}$ frame it was designed a solution made with M8 metallic connectors with a plastic disk with $6 \mathrm{~cm}$ diameter in the top, as can be observed in Figure $2 \mathrm{c}$ and $2 \mathrm{~d}$. Thus, the application of the strengthening followed the following steps:

1) Application of a first layer of plaster (thickness around $0.5 \mathrm{~cm}$ );

2) Placement and positioning of the net;

3) Fixation of the net with the connectors;

4) Application of a second layer of plaster $2 \mathrm{~cm}$ thick.

The mortar used for the application of the plaster was a current one, M5 class. It was applied five vertical strips with 1 meter width each, being the transition among them with $10 \mathrm{~cm}$ width. The transition between the panel and the frame elements was reinforced with two layers of net as recommended by the suppliers with a total width equal to $30 \mathrm{~cm}(15 \mathrm{~cm}$ in the panel plus $15 \mathrm{~cm}$ in the frame elements). The schematic layout of the strengthening strategy adopted is plotted in Figure 3. 
Furtado A., Rodrigues H., Melo J., Arêde A., Varum H.
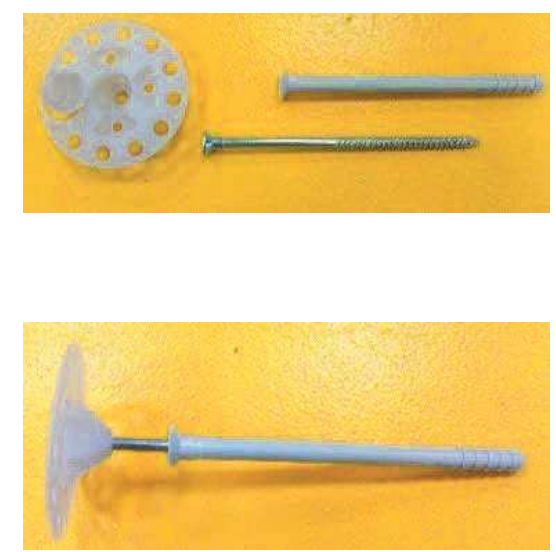

a)

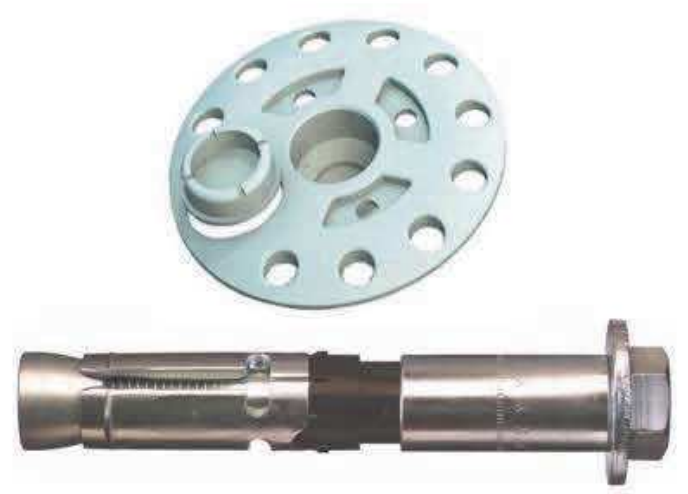

c)

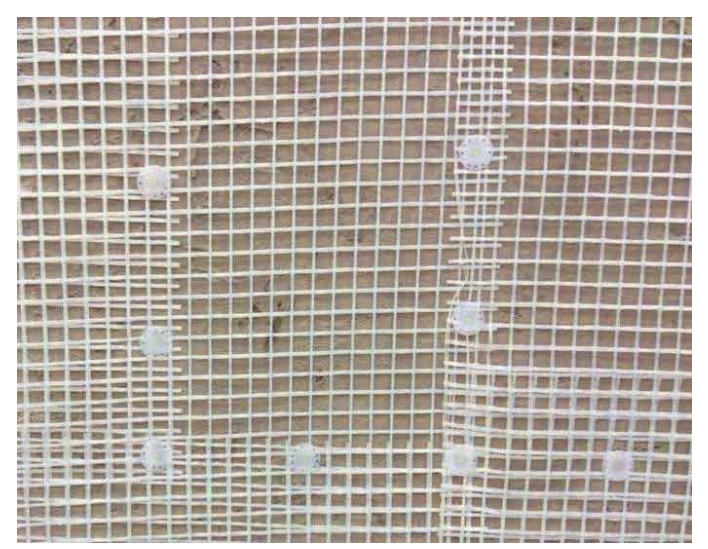

b)

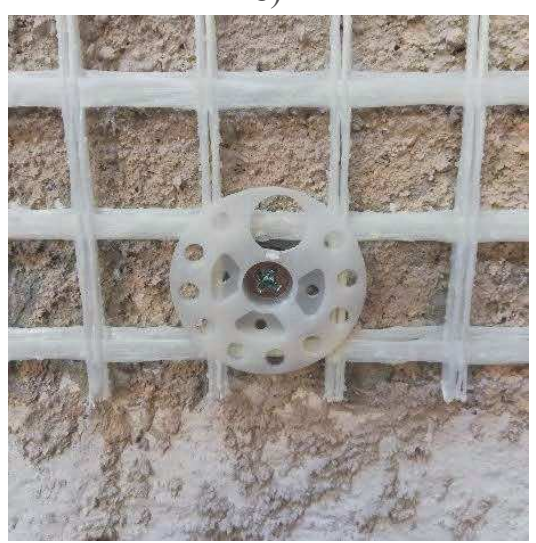

d)

Figure 2: - Retrofit application process: a) detail of the metalic connectors and plastic disk used in the panel; b) general view of the net fixed to the panel; c) detail of the M8 metalic connectors and plastic disk used to fix the net to the frame; and d) detail view of the application.

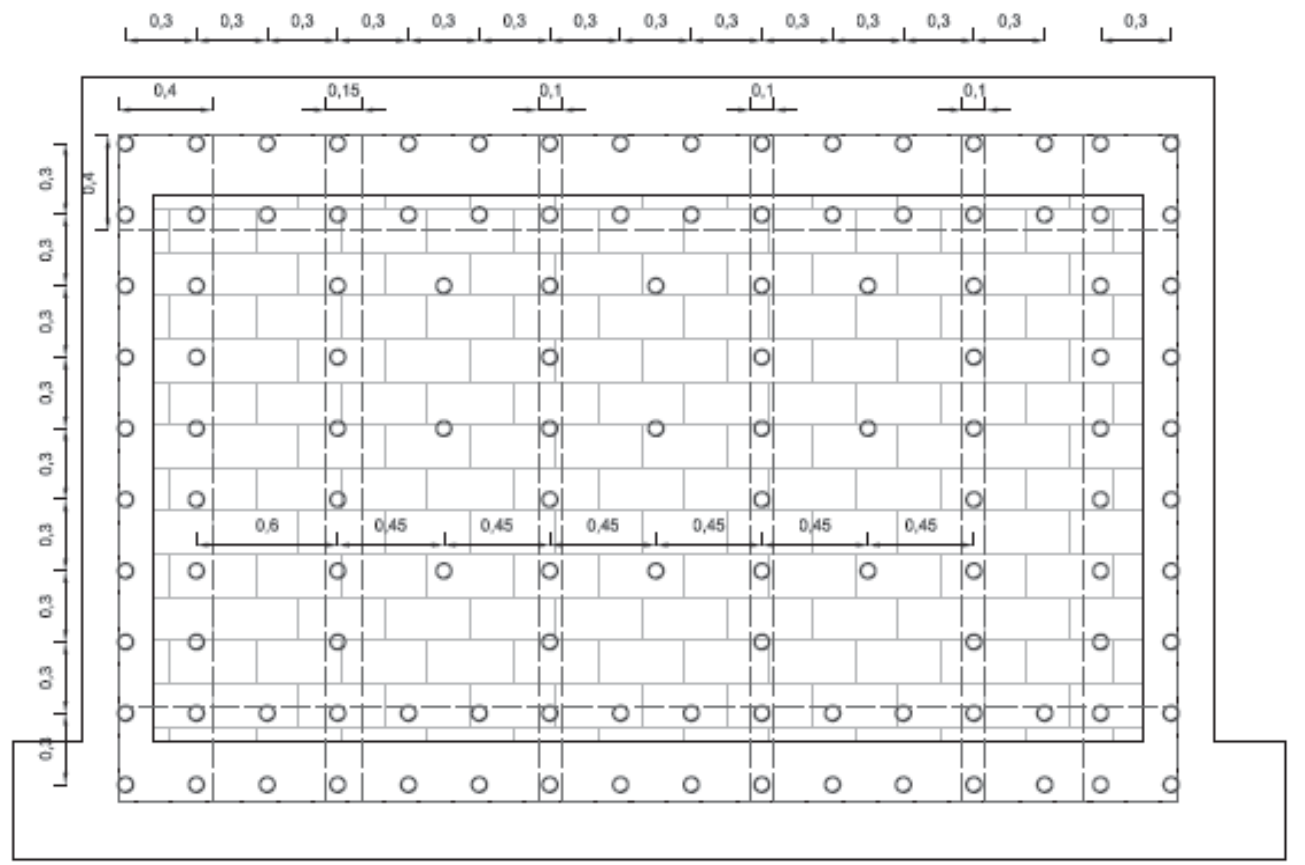

Figure 3: Schematic layout of the retrofit strategy (units in meters). 


\subsection{Test Setup}

The experimental test consisted on the application of a uniform OOP load applied by 28 pneumatic actuators, which are linked to a self-equilibrated reaction steel structure composed by four horizontal alignments made with HEB140 steel profiles and five vertical alignments made with HEB220 steel profiles (Figure 4). The vertical alignments are hinged, allowing their rotation during the tests. The steel reaction structure is attached to the envelope frame in twelve points (five in each top and bottom beam and one in each column). In each of these connections, it was placed a load cell that allowed to monitor the loads during the tests.

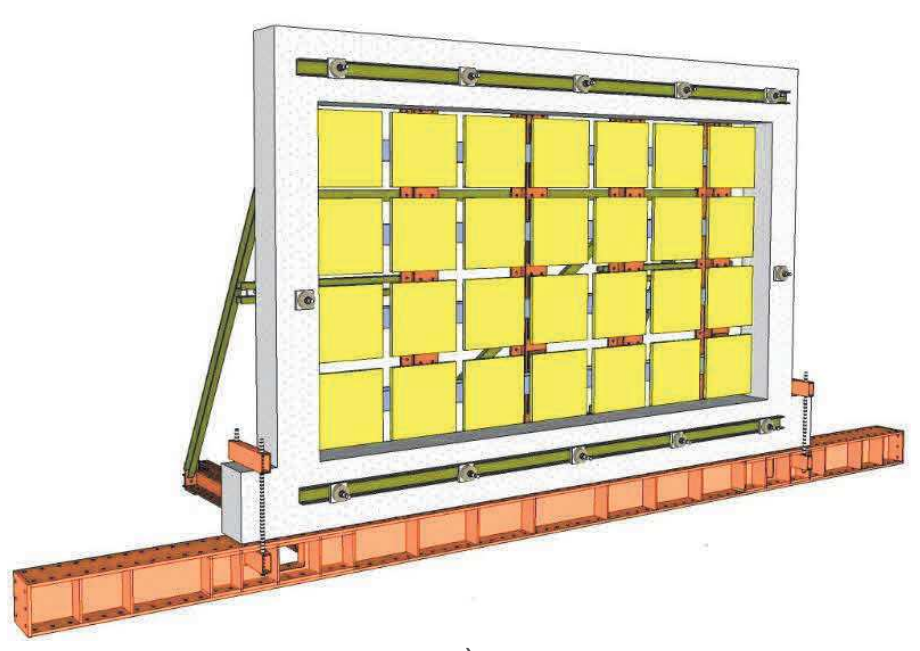

a)

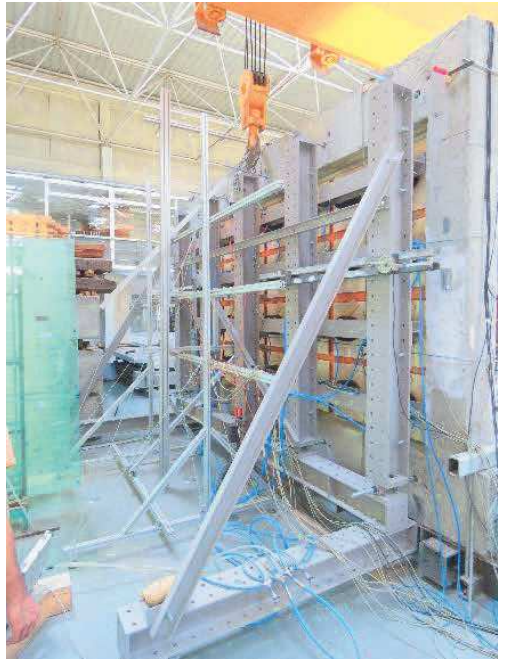

b)

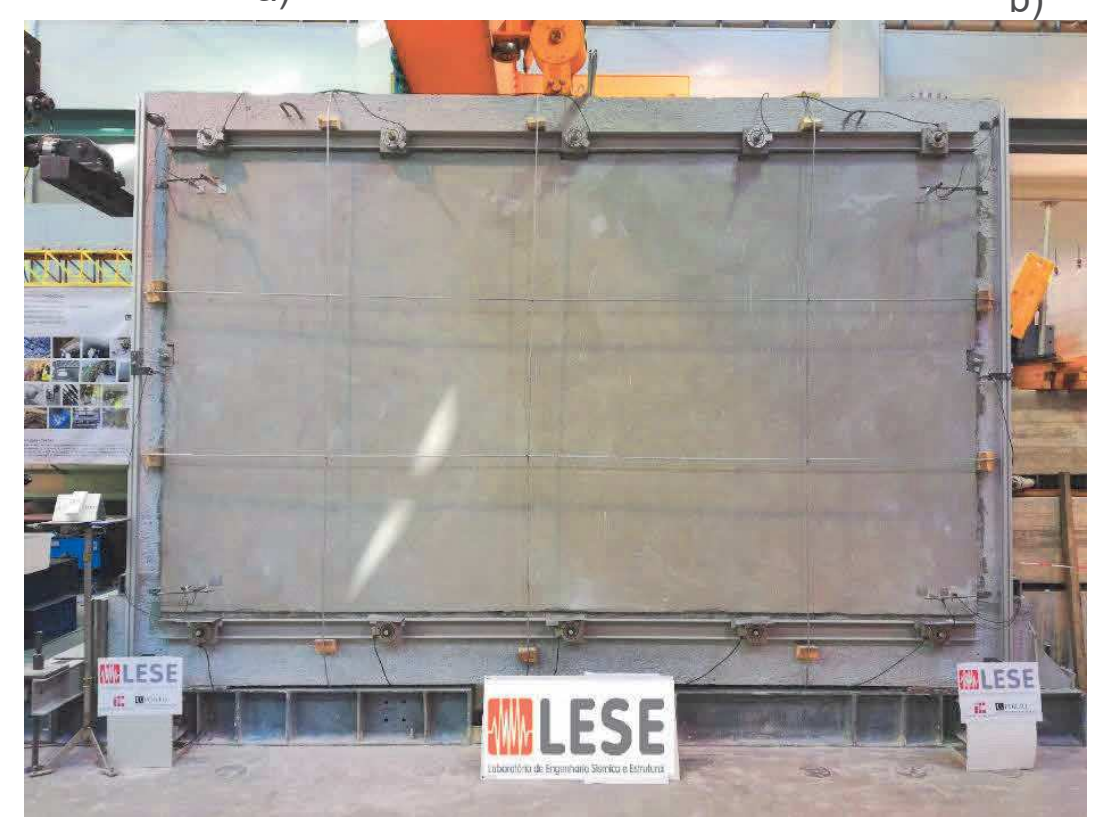

c)

Figure 4: Test setup: a) schematic layout; b) lateral view; and c) front view.

\subsection{Test Setup}

The instrumentation was composed by 21 displacement transducers, thirteen of them related to the monitoring of the panel OOP displacements and the remaining eight to the rotation between the panel and the envelope frame (Figure 5). Apart of that, and as explained in the previous subsection, twelve load cells were used to monitor the loadings developed during the test. The pressure level inside the pneumatic actuators was set by two pressure valves which were 
controlled according to the target and measured OOP displacement of the central point of the infill panel (the control node and variable) continuously acquired during the tests using a data acquisition and control system developed in the National Instruments LabVIEW software platform [7].

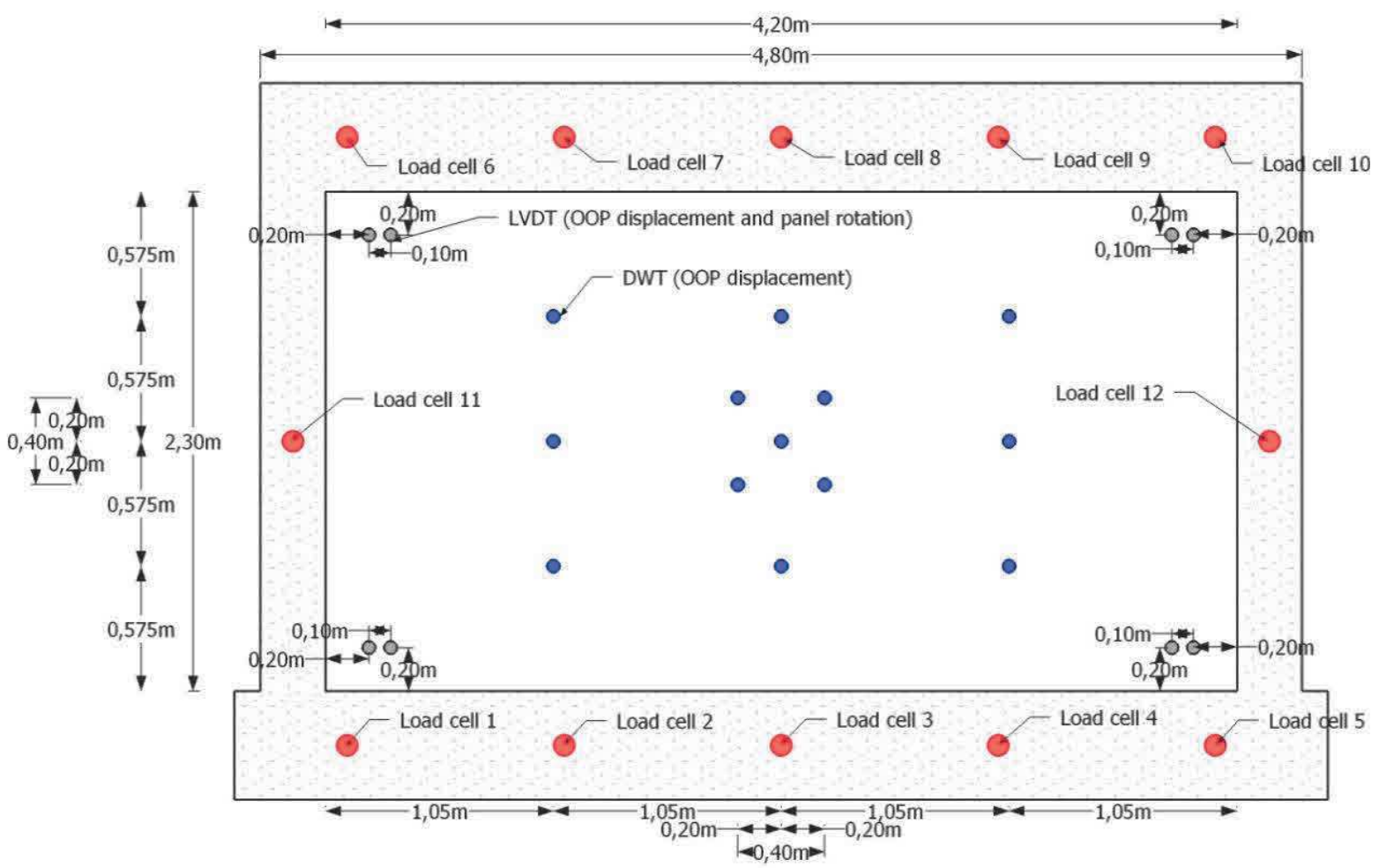

Figure 5: Test instrumentation - scheme layout.

Two half-cyclic (loading-unloading) OOP displacements were imposed with steadily increasing displacement levels, targeting the following nominal peak displacements: $0.5 ; 1 ; 2.5$; $5 ; 7.5 ; 10 ; 15 ; 20 ; 25 ; 30 ; 35 ; 40 ; 45 ; 50 ; 50 ; 55 ; 60 ; 65$ and $70 \mathrm{~mm}$. The central geometric point of the panel was selected as the control point since it was expected that is the region where it will occur the largest deformation of the panel.

\section{EXPERIMENTAL RESULTS}

The results of the two tests are here presented and discussed in terms of damages observed, cracking pattern and force-displacement results. In the first part of this section, the individual results will be detailed and later will be presented the comparison among the specimens to assess the efficiency of the strengthening solution.

\subsection{Specimen Inf_09}

During the test, it was not detected any damage until an OOP displacement equal to $5 \mathrm{~mm}$. At this level of OOP displacement occurred the plaster detachment in some parts of the panel. After that, at the OOP displacement equal to $7.5 \mathrm{~mm}$ it was observed the beginning of a horizontal cracking at $1 / 3$ of the panel height. When the panel reached the OOP displacement equal to $15 \mathrm{~mm}$, the horizontal crack becomes more pronounced and at the same time appeared a vertical crack at the middle of the panel, from the top until the horizontal crack. Quite often, when the OOP displacement reached $25 \mathrm{~mm}$ diagonal cracks were visible, which started in the same alignment of the horizontal crack until the bottom of the panel. At the end, at the OOP displace- 
ment equal to $30 \mathrm{~mm}$ it occurred the panel collapse. The cracking pattern was essentially trilinear as evidenced in Figure 6a. Figure $6 \mathrm{~b}$ and $6 \mathrm{c}$ presents the panel immediately before and after the collapse.
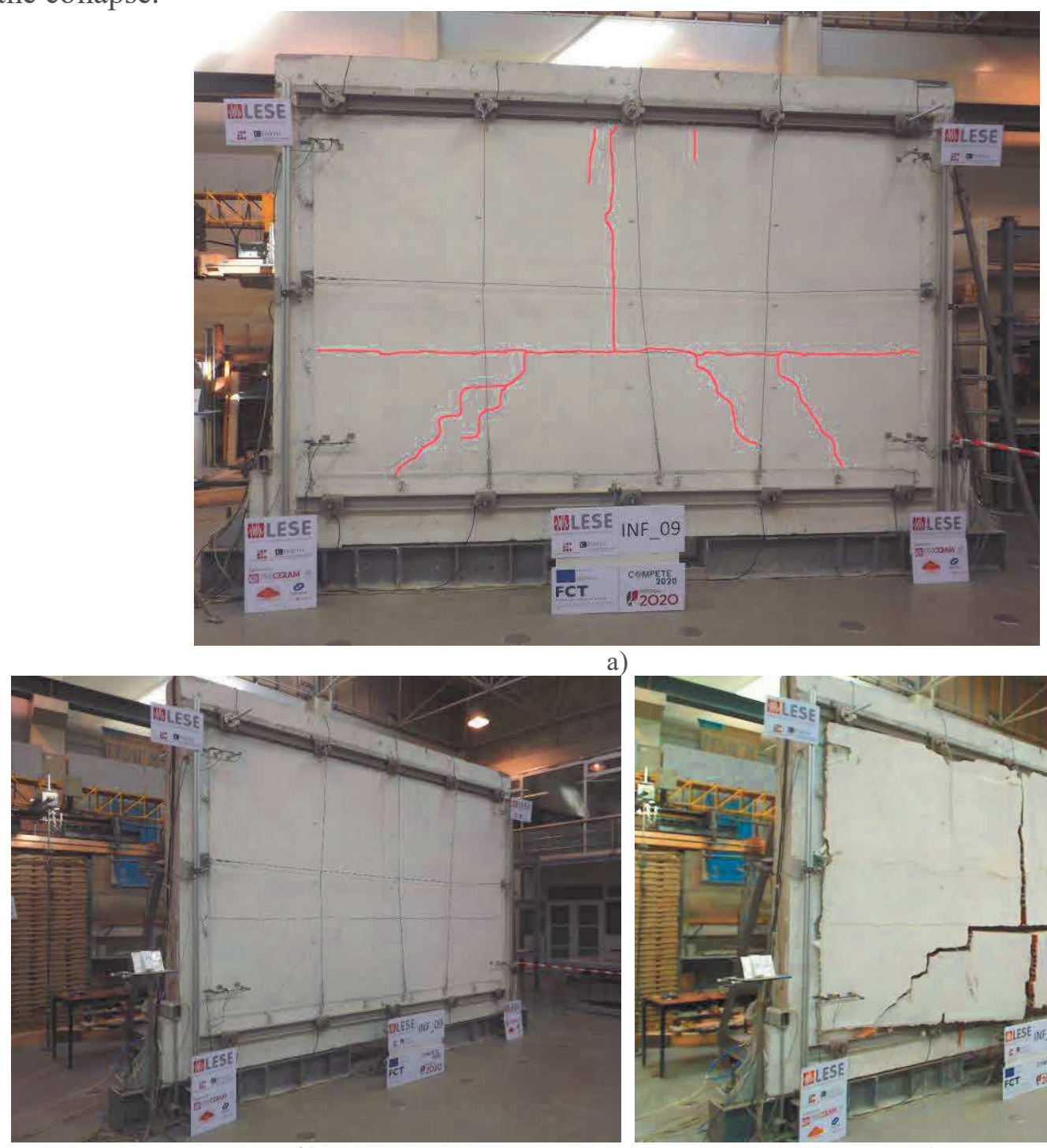

b)
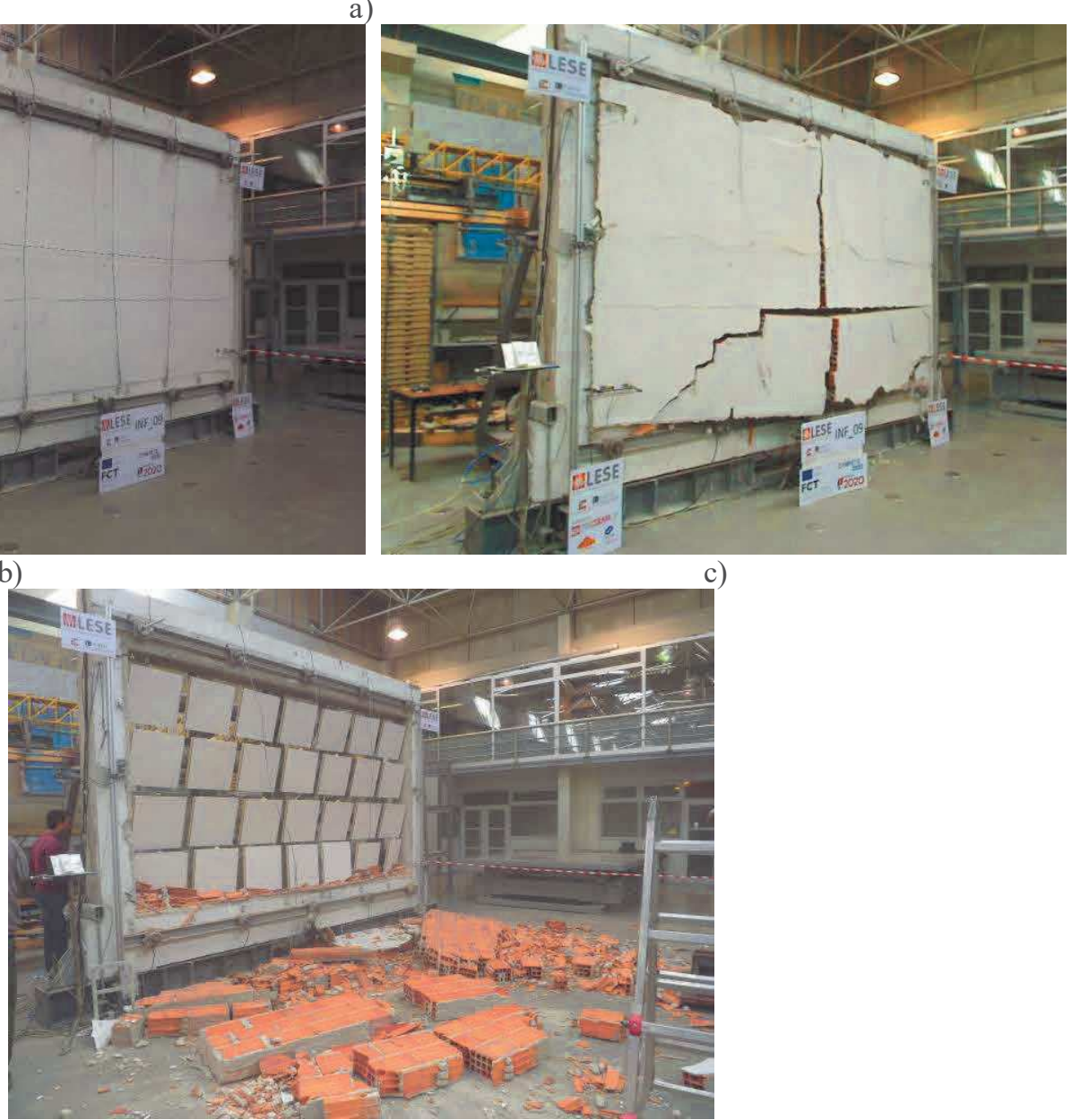

d)

Figure 6: Specimen Inf_09: a) Cracking pattern; b) Final damage before the panel collapse; c) Beginning of the panel collapse; d) Final damage after the panel collapse. 
Figure 7 presents the force-displacement response, from which it is possible to observe that for the OOP displacement equal to $2 \mathrm{~mm}$ occurred the first decrease of strength, which was quickly recover and followed by a progressive increase until the $6 \mathrm{~mm}$ (instant where it was visible the beginning of plaster detachment). After that, it can be verified a progressive increase of the OOP strength until reach a maximum peak load equal to $61.2 \mathrm{kN}$ which occurred for an OOP displacement equal to $29 \mathrm{~mm}$. Thereafter, at the OOP displacement equal to $29.8 \mathrm{~mm}$ occurred suddenly the panel collapse without any visible previous decrease of the OOP strength.

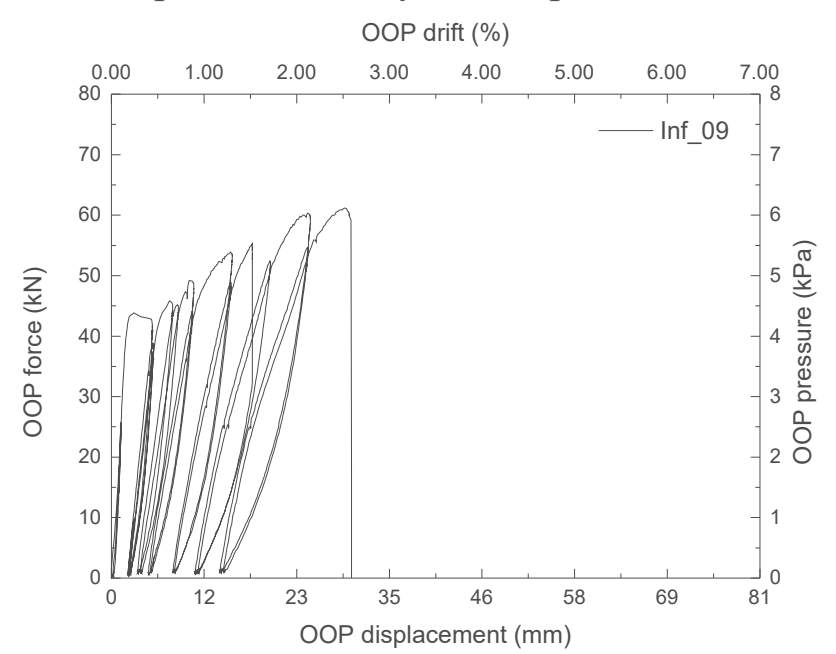

Figure 7: Specimen Inf_09: Force-displacement response.

\subsection{Specimen Inf_10}

During the test of the panel Inf 10, it was not visible any crack until the OOP displacement equal to $2 \mathrm{~mm}$, similarly to the panel Inf_09. At this moment it was noticed some plaster detachment. When the panel reached an OOP displacement equal to $10 \mathrm{~mm}$ it was visible a horizontal cracking at the same height as the one observed in the specimen Inf_09 (1/3 of the panel height). After that, at the OOP displacement equal to $20 \mathrm{~mm}$ two additional horizontal cracks parallel to the first one appeared the middle of the panel height and at $2 / 3$ of the panel height. Following that, small diagonal cracks occurred until the four corners of the panel. When the panel OOP displacement reached $30 \mathrm{~mm}$, the two horizontal cracks were more and more visible (placed at 1/3 and 2/3 of the panel height) and the corresponding diagonals developed from both to the panel corners. Finally, the panel reached the OOP displacement equal to $70 \mathrm{~mm}$ when it was visible a horizontal crack at the transition between the panel and the bottom RC beam (corresponding to the detachment of the panel from the frame). The panel collapse was prevented which allow to conclude that the strengthening solution was effective. Figure 8 presents the cracking pattern observed. 


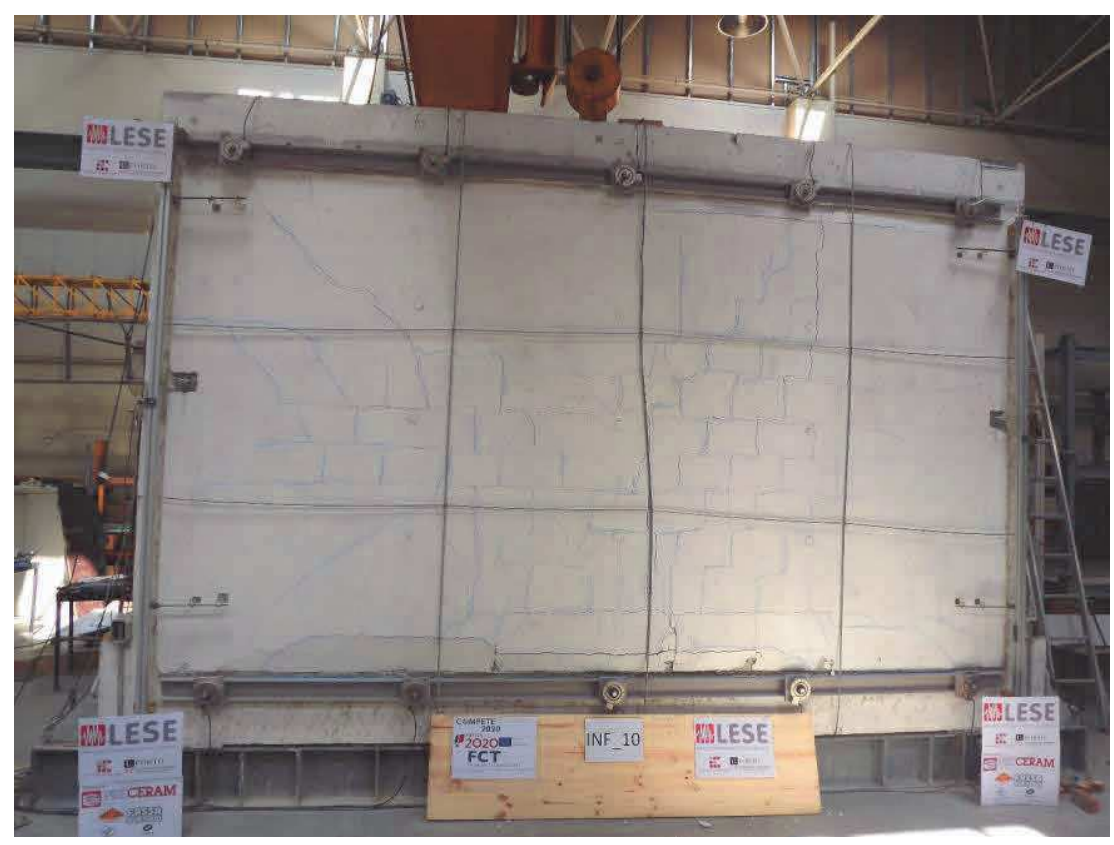

Figure 8: Specimen Inf_10: Cracking pattern.

From the force-displacement curve (plotted in Figure 9), it is possible to observe that the load increased progressively until reach the maximum peak load equal to $77.5 \mathrm{kN}$ (OOP displacement equal to $30.6 \mathrm{~mm}$, which basically means $1 / 5$ of the panel thickness). After this point, it was visible the beginning of the strength degradation. The displacement transducers were not capable to capture the maximum value of that displacement (which based on the remaining transducers allows to estimate that were around $50 \mathrm{~mm}$ ), because they exceeded their measuring range, however it was possible to measure the value of the residual displacement of the wall (about $41.9 \mathrm{~mm}$ ) and to restart the test from that point. After that moment, the stiffness degradation was enhanced, but still ten more cycles were possible to perform until reach the ultimate displacement equal to $71.7 \mathrm{~mm}$ without any strength degradation. The ultimate strength was $39 \mathrm{kN}$.

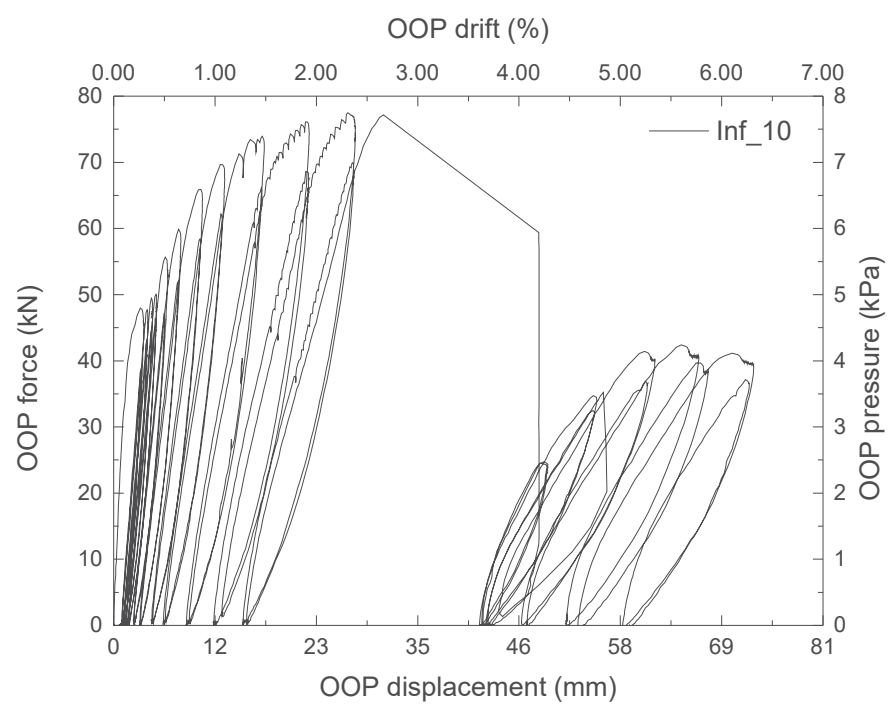

Figure 9: Specimen Inf_10: Force-displacement response. 


\subsection{Global comparison}

Through the comparison between both specimens, plotted in Figure 10, it is possible to observe that both reached similar initial stiffness, as well as the force corresponding to the appearance of the first cracking and the respective OOP displacement. Regarding to the maximum peak load, the strengthened specimen achieved an increment equal to $30 \%$ for an OOP displacement $5 \%$ higher. The major contribution of the reinforcement was the prevention of the OOP collapse and the possibility to achieve OOP displacements 2.5 times higher.

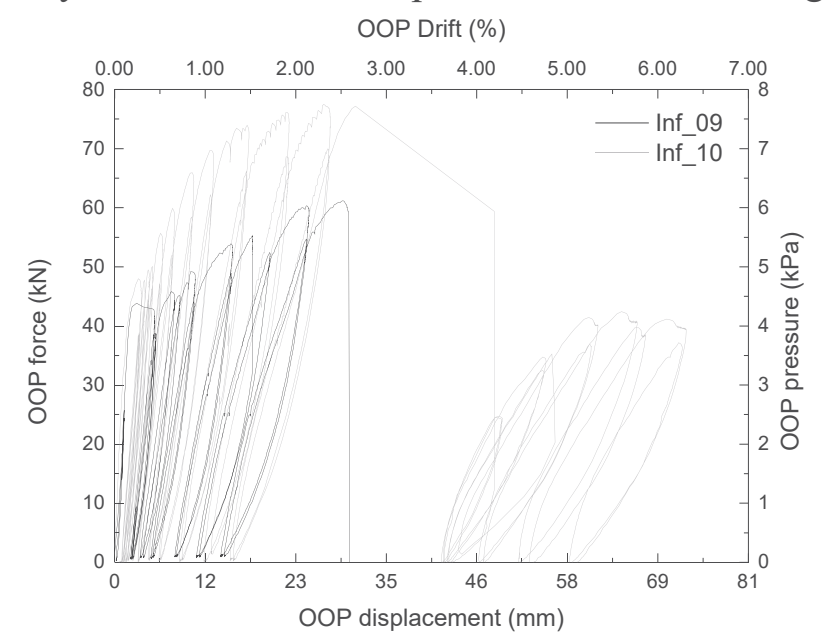

Figure 10: Global comparison: Force-displacement response of the Specimens Inf_09 and Inf_10.

\section{CONCLUSIONS}

In the assessment of existing buildings and in the design of new buildings, the consideration of the masonry infill walls presence should be mandatory as well as particular attention must be given to the connection of the panel to the envelope frame. Recent earthquakes evidenced that the infill panels are vulnerable to OOP loadings, which could result in serious human and economic consequences. Thus, the present work was carried out with the aim of assess the efficiency of a specific retrofit technique to improve the OOP behavior and prevent the panel collapse. The technique was textile-reinforced mortar by using a glass fiber net. Two specimens (one as-built and one strengthened) were tested under uniform OOP loadings applied by pneumatic actuators. The test of the as-built panel allow confirming the vulnerability of the panel, since it occurred the collapse without any prior decrease of the OOP strength. A trilinear cracking was observed without any detachment of the panel from the envelope frame. The retrofit technique revealed to be very efficient since it prevented the OOP collapse, improved the maximum peak load about $30 \%$ and the deformation capacity 2.5 times. The technique was very easy to apply and using traditional workmanship without spending long time during the application. Future tests will be carry out to assess the efficiency of similar solutions to combined in-plane and OOP loadings.

\section{ACKNOWLEDGMENTS}

The authors would like to acknowledge the support financially support by: Project POCI-010145-FEDER-007457 - CONSTRUCT - Institute of R\&D In Structures and Construction funded by FEDER funds through COMPETE2020 - Programa Operacional Competitividade e Internacionalização (POCI) - and by national funds through FCT - Fundação para a Ciência e a Tecnologia, namely through the research project P0CI-01-0145-FEDER-016898 - ASPASSI - Safety Evaluation and Retrofitting of Infill masonry enclosure Walls for Seismic demands. 
The authors would like also to acknowledge the material supplied by PRECERAM and Fassa Bortolo for this experimental campaign.

Finally, the first author would like to gratefully acknowledge the financial support from the international scientific journal Buildings, specifically by the attribution of the "Building Travel Awards 2019”.

\section{REFERENCES}

[1] L. Hermanns, A. Fraile, E. Alarcón, and R. Álvarez, "Performance of buildings with masonry infill walls during 2011 Lorca earthquake," Bull Earthquake Eng, vol. 12, pp. 1977-1997, 2014.

[2] F. Luca, G. Verderame, F. Goméz-Martinez, and A. Pérez-Garciía, "The structural role played by masonry infills on RC buildings performaces after the 2011 Lorca, Spain, earthquake," Bull Earthquake Eng, vol. 12, pp. 1999-2026, 2014.

[3] X. Romão et al., "Field observations and interpretation of the structural performance of constructions after the 11 May 2011 Lorca earthquake," Engineering Failure Analysis, vol. 34, pp. 670-692, 2013.

[4] A. Furtado, H. Rodrigues, A. Arêde, and H. Varum, "Out-of-plane behavior of masonry infilled RC frames based on the experimental tests available: A systematic review," Construction and Building Materials, vol. 168, pp. 831-848, 4/20/ 2018.

[5] P. Ricci, M. Domineco, and G. Verderame, "Empirical-based out-of-plane URM infill wall model accounting for the interaction with in-plane demand," Earthquake Engineering \& Structural Dynamics, 2017.

[6] A. Furtado, H. Rodrigues, A. Arêde, and H. Varum, "Effect of the Panel Width Support and Columns Axial Load on the Infill Masonry Walls Out-Of-Plane Behavior," Journal of Earthquake Engineering, pp. 1-29, 2018.

[7] R. Vicente, H. Rodrigues, H. Varum, A. Costa, and R. Mendes da Silva, "Performance of masonry enclosure walls: lessons learned from recent earthquakes," (in English), Earthquake Engineering and Engineering Vibration, vol. 11, no. 1, pp. 23-34, 2012. 